\title{
EDITORIAL
}

\section{Social distancing to combat COVID-19: We are all on the front line}

\author{
Kirsten Patrick MB BCh MSc, Matthew B. Stanbrook MD PhD, Andreas Laupacis MD MSc
}

Cite as: CMAJ 2020 May 11;192:E516-7. doi: 10.1503/cmaj.200606; early-released April 8, 2020

See related research at www.cmaj.ca/lookup/doi/10.1503/cmaj.200457 and www.cmaj.ca/lookup/doi/10.1503/cmaj.200476

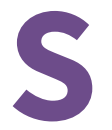

elf-isolation of people with mild coronavirus disease 2019 (COVID-19), quarantine of those exposed, and social distancing for the rest of us constitute Canada's current reality. New research has modelled the probable effects of self-isolation ${ }^{1}$ and different approaches to social distancing ${ }^{2}$ on the demand for critical care services in Canada. The results are sobering.

Shoukat and colleagues find that without social distancing even faithful adherence to self-isolation directives for those infected with severe acute respiratory syndrome coronavirus 2 (SARS-CoV-2) will not prevent critical care services from being overwhelmed in all Canadian provinces. ${ }^{1}$ Tuite and colleagues, modelling Ontario data and looking instead at the effects of social distancing, find that only strict social distancing measures of long duration will flatten the epidemiological curve. ${ }^{2}$ They modelled over 2 years both "fixed" social distancing, in which strict measures remain the same over time, and "dynamic" social distancing, in which strict measures are intermittently relaxed and reintroduced based on thresholds of intensive care unit (ICU) occupancy.

Dynamic social distancing amounts to gaming of the epidemiological curve, allowing COVID-19 case numbers to wax and wane over time so long as a manageable burden is maintained for critical care services. Tuite and colleagues consider that such an approach, while achieving the goal of not overwhelming our health systems, would also allow people some respite from the psychological and other adverse health effects of prolonged physical distancing and possibly mitigate some economic effects too.

Long-term social distancing will be tough, but current best estimates make it clear that if we don't do it we will see Canada's health systems buckle like those in Italy and New York. Not doing it well would mean too many avoidable deaths, national grief and health care workers being subjected to the terrible moral injury of having to choose who gets access to life-saving resources. The findings of the modelling studies underscore a point made many times in recent weeks: health care workers are not the front line; they are our last line of defence.
Although some of us have quickly adjusted to new normals, such as physical spacing at grocery stores and working from home, social distancing is already unbearable for people without a home in which to shelter, those who may be exposed to harm at home and those who have lost their employment. Communities will need to organize to support vulnerable people to selfisolate or practise social distancing.

Canada's public health leaders and politicians, some of whom have been fierce adversaries, appear to be working well together to deliver consistent messaging. Given this new evidence, however, our leaders now need to communicate clearly that Canadians will likely need to embrace social distancing for much longer than previously indicated. If people in the community are the front line, then presenting evidence transparently and acknowledging uncertainties will be essential to maintain their trust.

All models are limited by their assumptions and the data available to run them. This is exemplified by the quite different assumptions made by the authors of the 2 modelling studies and their use of different sets of data available at different times. Enhanced capacity to test for SARS-CoV-2 in Canada might change the data feeding into models and result in different projections. Observed rates of illness among health care workers may lead to altered assumptions about ICU capacity. However, planning with the results of limited models is preferable to planning without them.

With a preventive vaccine unlikely to be widely available in the next couple of years ${ }^{3}$ and no antiviral treatment of certain effect currently available, COVID-19 is going to threaten Canada's health systems for a long time. These 2 quite different models confirm that short-term public health measures, incompletely observed, will do nothing but delay the time until our critical care capacity is overwhelmed. That means it's time for our leaders to trust the public with the truth about long-term measures and be explicit about what people need to anticipate. It's time for governments to build on initiatives such as housing homeless people in hotel rooms and supplementing lost income to ensure that all people in Canada can practise social 
distancing safely and with as little hardship as possible. And it's time for people practising social distancing to understand their immense responsibility at the front line. Health care workers, and future patients, are depending on all of us to slow the spread of SARS-CoV-2.

\section{References}

1. Shoukat A, Wells CR, Langley JM, et al. Projecting demand for critical care beds during COVID-19 outbreaks in Canada. CMAJ 2020 Apr. 8 [Epub ahead of print]. doi: $10.1503 / 200457$.

2. Tuite AR, Fisman DN, Greer AL, et al. Mathematical modelling of COVID-19 transmission and mitigation strategies in the population of Ontario, Canada. CMAJ 2020 Apr. 8 [Epub ahead of print]. doi: 10.1503/200476.

3. Lurie N, Saville M, Hatchett R, et al. Developing COVID-19 vaccines at pandemic speed. N Engl J Med 2020 Mar. 30 [Epub ahead of print]. doi: 10.1056/ NEJMp2005630.

Competing interests: See www.cmaj.ca/site/misc/cmaj_staff.xhtml

Affiliations: Executive editor, CMAJ (Patrick); deputy editor, CMAJ (Stanbrook); Department of Medicine (Stanbrook), University of Toronto, Toronto, Ont.; editor-in-chief, CMAJ (Laupacis).

Correspondence to: CMAJ editor, cmaj@cmajgroup.ca 